\title{
TIME AND SPACE OF HERITAGE PRESERVATION: CONSERVATION THEORETICAL PERSPECTIVE
}

As human beings, we simultaneously live in a physically existing environment and the cultural image of the same environment. On the one hand, we have direct physical contact with the environment; on the other hand, it is also mediated and cultural. Our existence in the world is one of the cornerstones of our humanity. What combine in the world are both the actual environment that is the foundation of our existence and the discourse that people have constructed of it. Time and space are the two main categories of the physical existence of humans, but not only that: treatments of time and space make up one of the most significant parts of the deep structure of culture. We ourselves are positioned in time and space, and the background to all of our thoughts and feelings is also time and space. Preservation is the maintenance of meanings and values. Upon attempting to connect meanings and values to time and space, it seems that meanings tend to be more spatial and values more temporal. Meanings are related to space; in another word, the environment. According to biosemioticians, the emergence of meaning is related to the emergence of life. Before life emerged on planet Earth, there were no meanings present; these slowly started to 
appear as life developed. ${ }^{1}$ In such a general sense we can understand meanings as the employment of environmental differences by living organisms. The actual explosion of the meaningful world took place with the emergence of the modern human, of course. Meanings seem to accumulate and gather; values, however, tend to emerge and disperse.

Although time and space make up the main categories of our world, their relationship to cultural heritage and its preservation have often been left out of theoretical discussions. According to Juhan Maiste, "the task of heritage conservation is not merely to speak of matter nor ideas but rather of both of them; instead of empty space, we should speak of filled space where something is happening at each and every moment; where the instinctual desire to preserve ourselves is also related to the overwhelming desire in ourselves to go on, to create something new instead of what we have already lived, to build bridges between tradition and innovation. And yet, the task of heritage conservation is mostly not to create time and space, not even to ask overly complicated questions about them." ${ }^{2}$ I think it is the contrary: not only do we need to ask these complicated and contradictory questions, but we also need to understand that creating time and space is one of the main tasks and goals of preservation. In addition to the fact that heritage is inevitably located in time and space, preservation also directly needs to deal with shaping space and understanding time. Otherwise we fail to understand heritage, and to connect its preservation to the development of societies and the flow of understanding the world.

In this article I am treating the categories of time and space through heritage preservation. I am showing that heritage creation is also the creation of human time and space, and that critical treatment of heritage also requires a more precise distinction of these main terms. First I will look at how human space is created via objects, how the objects of physical environment become parts of our life and world - things. One can only change the world by understanding it. This is a fundamental truth which is the foundation to both common sense and complicated philosophies. In order to explain the changes

1 See, e.g. Jesper Hoffmeyer, Biosemiotics: An examination into the Signs of Life (Chicago Chicago University Press, 2009).

2 Juhan Maiste, "Aeg ruumis ja ruum ajas. Tagasi asjade juurde", Aeg ja ruum. Uue muinsuskaitse poole, ed. by Anneli Randla (Tallinn: Eesti Kunstiakadeemia, 2009), 9-16, 10 in space related to heritage, I will use the terms "artificialisation" and "heritage technology". This is not an attempt to present the history of how time and space have been treated in conservation and restoration; instead, I will focus on more significant theoretical key points and use them to characterise the importance of these terms for the field of heritage.

\section{CREATING HERITAGE SPACE THROUGH TECHNOLOGY}

The two largest metaphors around which we create a network in order to make our life meaningful are nature and culture. The world of heritage is located in the ambivalent fields of the natural and the cultural. Heritage space is created by people through the phenomena and objects that we call heritage. Creating heritage space is an activity belonging to the field of technology. In order to understand it, we need to start with culture.

The following is a discussion of culture in its wide anthropologic sense, meaning a way of life characteristic to groups of people. Culture in this wider sense is unquestionably a vital condition for the existence of human species. Culture is a phenomenon unique to humans, although culture has not emerged solely with the development of humans. However, while other animal species might also have their own protocultures, Homo sapiens is nevertheless the only species whose cultural transmission is stable enough for coevolution with a genetic heredity system. Culture is quite clearly the key element that distinguishes us from other organisms to a significant extent, enabling us to share knowledge among ourselves and pass it on to our descendants. The extremely adaptable and flexible human nervous system is, on the one hand, conditioned by the artificial environment surrounding us; on the other hand, however, it is vital in order to create such an environment. The emergence of such a reciprocal influence cycle has been the foundation of the development of the human species. The creature that we call a thinking human being is made up of the synergy of the physical human body (especially the nervous system), culture, and the environment; whereas the tools and technologies used by people are simultaneously the result and the determining factors of our human activity. The complicated nervous system that uses the transmission system of biological and genetic information inevitably needs to combine with culture. Unless we have 
a sufficiently complicated nervous system, we are unable to create and use culture. However, even the most complicated nervous system is useless with a lack of culture. As we can see, it is impossible to draw a distinction between a human being as a biological creature and a human being as a cultural creature. We are a complicated combination of both, and this is what makes us unique - at least among all the organisms inhabiting the planet Earth.

When a human being is born, they have no ready-made culture; however, neither is culture directly taken over from the environment one ends up in. Acquiring a culture also means changing and shaping the culture in interaction with a person's biological development. As a person grows and develops, also culture is created, which grows and develops just as the biological human body and nervous system. Culture has come to be such that it is able to mutually interact with the human brain, and our brain has developed into being such that very different cultural features can stimulate it, triggering the recognition of certain features and patterns.

Different parts or fields have been distinguished in culture. One widely used distinction is the division of culture into material (i.e. tangible) and non-material (i.e. intangible) culture. The material culture can also be defined as "the sector of our physical environment that we modify through culturally determined behaviour". ${ }^{3}$ This is a very broad definition including not only man-made objects (artefacts) but also the parts of the natural environment that people have changed according to their needs. On the one hand, a piece of rock collected by a geologist or insects captured by a biologist are natural objects; on the other hand, they are also artefacts, as they have been removed from their original context and are being preserved for scientific purposes (Fig. 1). Non-material culture is made up of values and beliefs, social norms, and all kinds of symbolic systems (language, numbers, and art). Non-material culture encompasses people's thoughts and behaviour, their ideas, and all sorts of abstract entities - but also organisations and institutions. Sometimes, two types of artefacts are distinguished when discussing culture: material objects and non-material objects, i.e. mentefacts. Whereas material objects are concrete and perceptible objects, mentefacts refer to

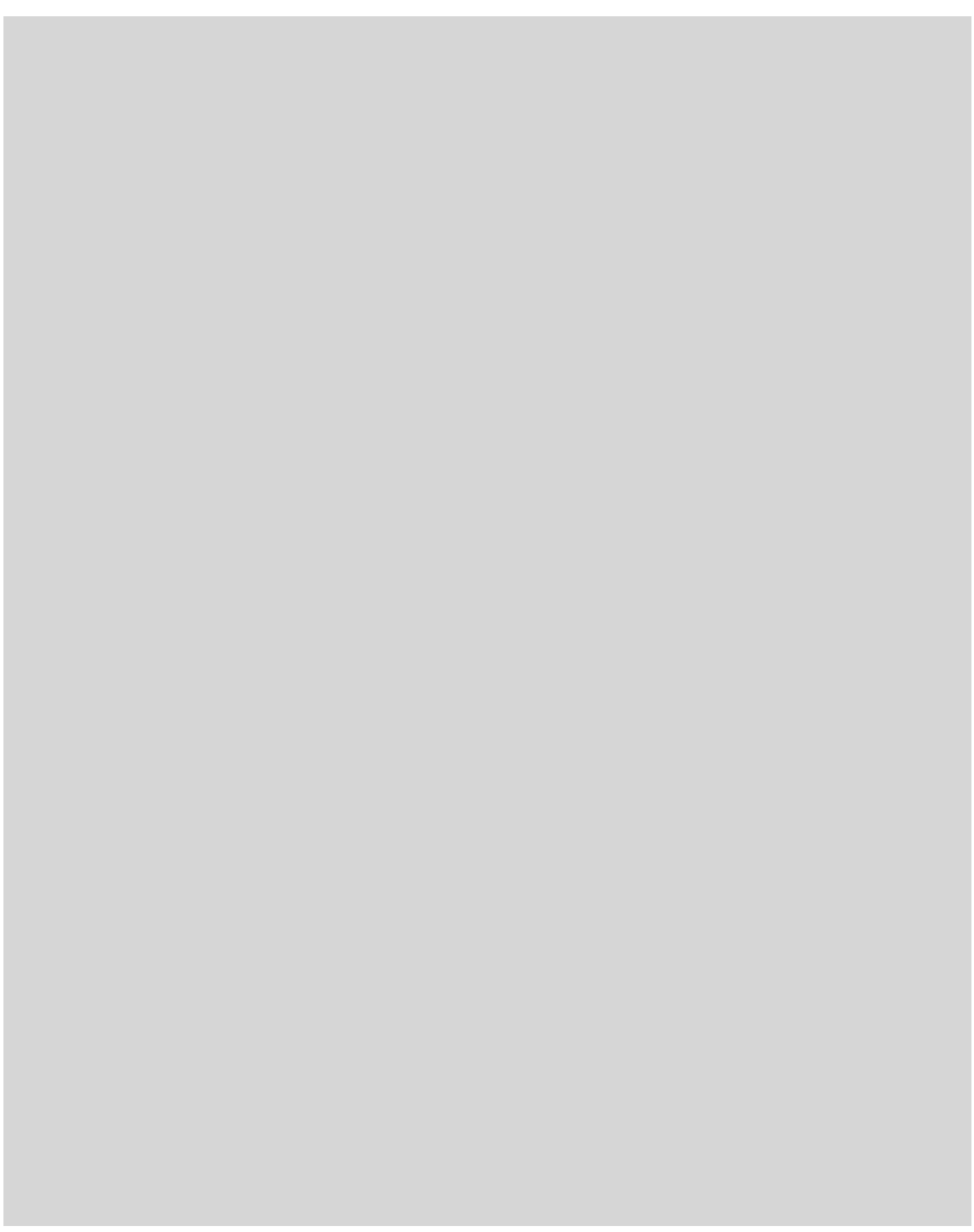

Fig. 1. A leaf from the herbarium of vascular plants at the Natural History Museum at in a muveusty or in a scientific institution becomes an artefact. Photo: Kand

abstract information, leaving the physical carrier aside. Examples of mentefacts are text, graphics, databases, music, etc. In fact, both aspects of culture are inseparably connected, and the distinction is needed mostly due to the differences of scientific disciplines, but also out of practical necessity. 


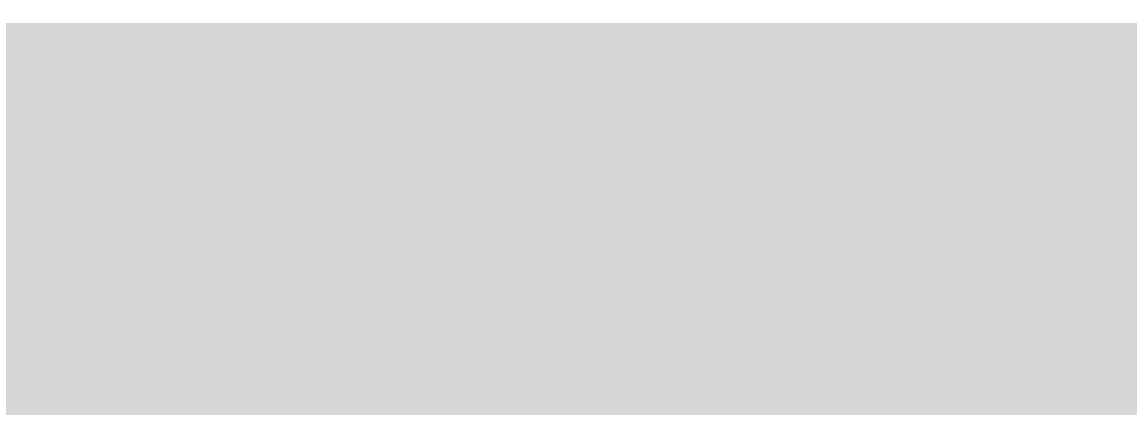

Fig. 2. Objects becoming things and heritage. Drawing by Peeter Laurits.

When focusing on things surrounding people, what needs to be emphasised immediately is the importance of these things to people. Things are an important part of our world, of our lifeworld. We are connected to the world through things. We use them to express our thoughts and feelings. We think through them and with their help. There is a huge difference between a natural object and an item that has been paid attention to by a human being. In the human world, objects connected to meanings and values become things, some of which will in turn become heritage (Fig. 2).

People live in the world, but the world is to a large extent made by ourselves. We live in a mostly artificial environment filled with manmade objects. These objects can be relatively simple, such as the chair I am sitting on, or highly complicated, like the computer on the desk in front of me. Things do not just emerge by themselves; technology is needed for that. Being a human is inseparably related to several tools, technologies, inventions, and activities. Technology connects our lives, identities, and activities; it also participates in the creation of our place in the world, and our identity. Living our cultural and social life as biological creatures in this world rearranged by people, it is important for us to recognise and be familiar with technology. This is all also directly related to heritage: heritage is a technology that has to be used as efficiently as possible to solve local and global problems of both contemporary and future societies.

Unless we do that, heritage will become unnecessary and disappear, at least in the sense developed at the end of the $18^{\text {th }}$ century and used until now. The idea of heritage as a technology is related to the idea of heritage as a social construct. Treating heritage as a technology that is being created right now allows societies to prevent the use of heritage in the justification and support of nationalism, separatism, and oppression. Heritage is not connected to the essential nature or past events of nations or groups of people. Heritage is a technology that we use nowadays to create the present and the past; it is dependent not only on the past but also on our current choices. Heritage is merely a tool; however, it should not be forgotten that it is a very powerful tool for making these choices and carrying out decisions. The fact that society's functioning processes and structures are becoming increasingly complicated also has an effect on the field of heritage. Both recognising something as heritage and managing it has become a task of respective institutions and experts. However, the desire of individuals and communities to manage heritage in correspondence with their beliefs and goals has also strengthened.

Heritage is simultaneously a part of our physical reality, and a non-material phenomenon (Fig. 3). Heritage connects people to each other and the environment, both to its material and natural aspects, being therefore one part of our world. Based on our heritage, by re-creating heritage again and again and loading it with meanings important to them, people shape the way societies function. It is through heritage that meanings are created and values are presented to societies and to society at large. I categorise the heritage process as a broader technology, treating it as a specific technology through which people employ their past and implement it to meet their present needs. It is part of the process by which the world is becoming more artificial. The term "technology" has several definitions, as it is a complex phenomenon that is difficult to treat.

The most wide-spread view of technology is that of a collection of tools and machines. It is obviously too narrow a definition since it excludes all technologies that do not use tools. According to Lewis Mumford, the first tool in the world history was organisation, which allowed a huge number of people to come together to do some kind of work. He called this kind of social organisation a "megamachine". ${ }^{4}$ Different types of definitions consider technology via rules rather than tools. Jacques Ellul views the essence of technology as a behaviour

4 Lewis Mumford, "The concept of the megamachine", Philosophy of Technology: The Technological Condition, an Anthology, ed. by Robert C. Scharff, Val Dusek (Oxford: Blackwell, 


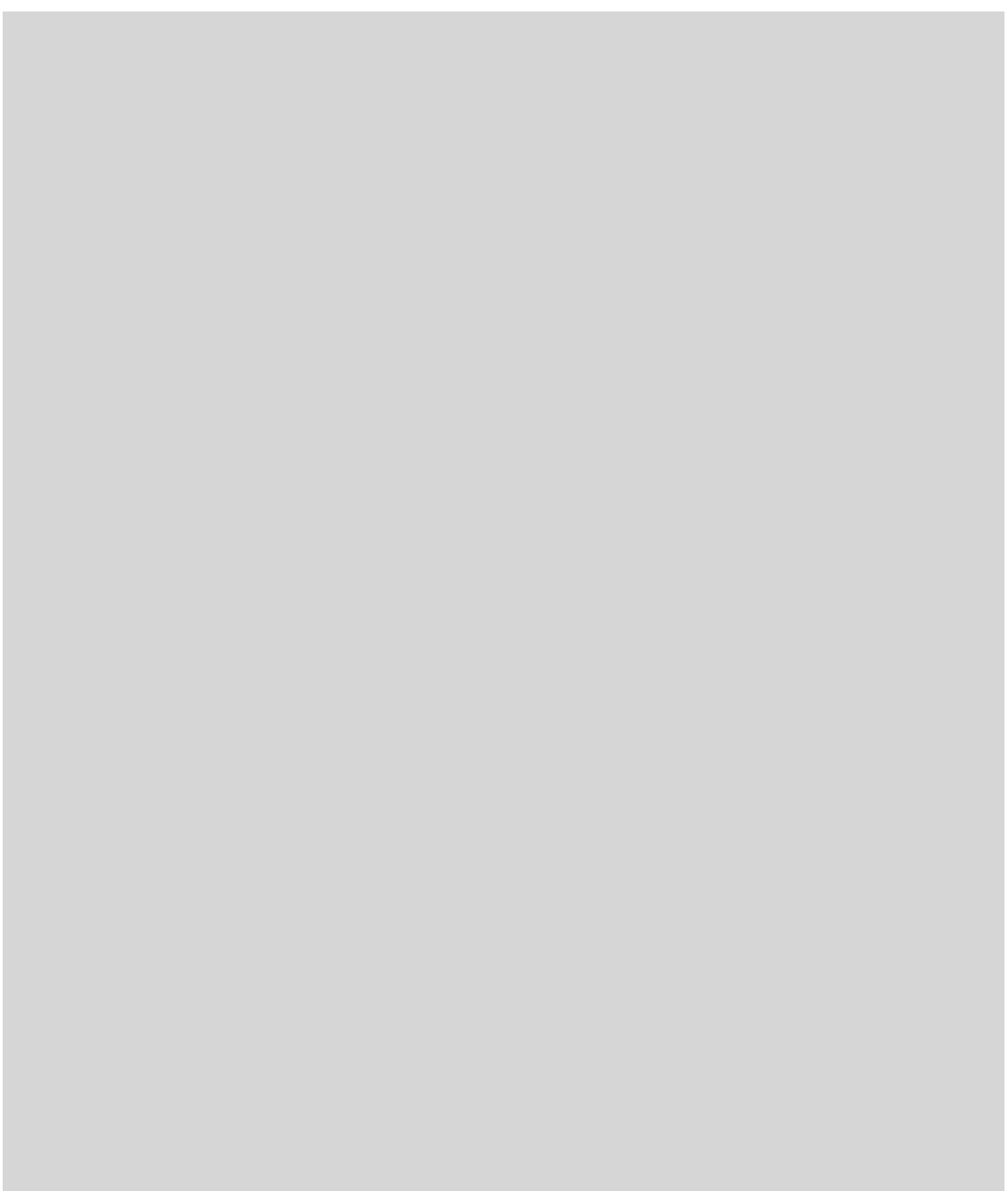

Fig. 3. The iconostasis in the prayer house of the Raja congregation of the Old Believers Heritage is simultaneously a part of our physical reality and a non-material phenomenon. Photo: Kurmo Konsa.

following certain norms. ${ }^{5}$ Psychologist Burrhus Frederic Skinner adds here interpersonal manipulations and behaviour management. ${ }^{6}$ The danger of such definitions is that they become too "comprehensive":

5 Jacques Ellul, "The Technological Society", Philosophy of Technology: The Technological Condition, an Anthology, ed. by Robert C. Scharff, Val Dusek (Oxford: Blackwell, 2002), 182-186.

6 Burrhus Frederic Skinner, Beyond Freedom and Dignity (New York: Knopf, 1971). by blurring the line between technology and culture, the whole of culture and society are covered by the term "technology". The third type of definition emphasises the vital importance of a human context for technology. By adding social organisation and human values to the definition of technology, the definition of a technological system could be as follows: "Technology is the systematic application of scientific or other organized knowledge to practical tasks by organized systems that involve people and machines." ${ }^{\prime 7}$ Based on this definition of technology, in case of heritage process, we can speak of it as a specific technology. What is it then that heritage technology deals with? Technology is the main way for humankind to adapt to, and change, the environment. Technology itself and its influence on the environment are to a large extent intermediated by culture. Technology is one of main ways for human society to relate to the natural environment. In the words of Arthur McEvoy: “Technology is what distinguishes human activity in nature from that of other animals; because technology is a means of interacting with nature, however, it should be amenable to ecological analysis." ${ }^{8}$ This kind of development has once again raised the issue of determining the relationship between technology and culture. Since technological systems are man-made, they undoubtedly also affect human society and culture. Several theories have been created to describe and explain this phenomenon; however, there are not many treatments that include culture, technology and the environment at the same time. Here we could mention Bruno Latour, who has criticised the distinction between nature and culture, claiming that man-made objects should be treated as "actants" and therefore as symmetrical to humans. According to Latour, the starting point for such analysis is the nature-culture hybrid. ${ }^{9}$ The actor-network theory created by Latour has also been used to discuss heritage. ${ }^{10}$ It seems to me that one of the most significant foundations of human existence is the fact that to live as a human being on this planet means changing this planet. To my mind, "artificialisation" is a fitting term to describe all

7 Arnold Pacey, The Culture of Technology (Cambridge: MIT Press, 1983), 6.

8 Arthur McEvoy, "Working Environments: an Ecological Approach to Industrial Health and Safety", Technology and Culture. Supplement: Snapshots of a Discipline, 36 (1995), 150. 9 Bruno Latour, We Have Never Been Modern (Cambridge: Harvard University Press, 1993).

10 Rodney Harrison, Heritage: Critical Approaches (New York: Routledge, 2013), 31-35. 


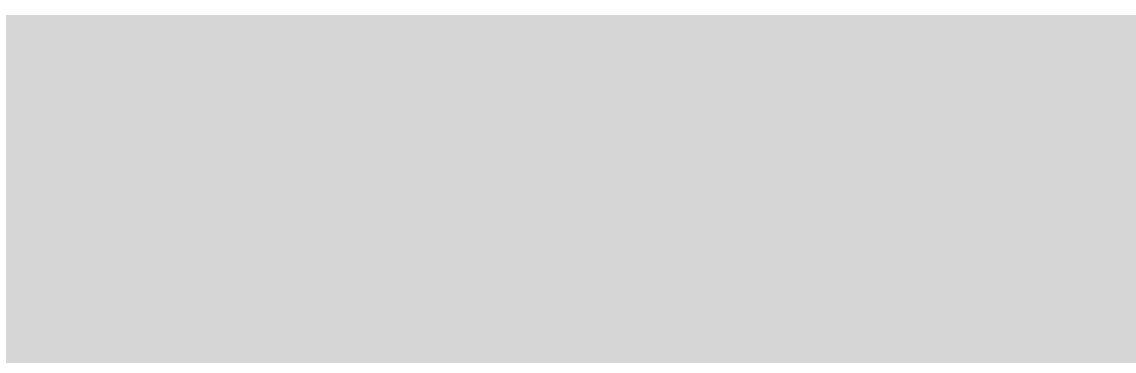

Fig. 4. Presentist time model. The only thing that really exists is the present. Drawing by Peeter Laurits.

these changes. By artificialisation, I understand an anthropogenic transformation of the environment that mainly takes place through the effect of a technological system. The environment hereby encompasses the physical, biological, and genetic life environment, as well as human culture, including its past. In this environment, it is impossible to distinguish between the human and the inhuman, since these make up one hybrid whole. ${ }^{11}$ The term "artificialisation" allows an easier crossing of the still-existing semiotic line, as Christina Ljungberg calls it, between nature and everything artificial. ${ }^{12}$ In terms of artificialisation, we are not speaking about a line but a complicated process. This term is not as politicised as are the categories of technology and nature. Of course, artificialisation does not imply any determined course of history; it is a human means of description, a metaphor to help explain the processes ongoing in nature and in human society. According to this treatment, heritage process would be one technology employed in the artificialisation of the environment.

\section{TIME MODELS AND HERITAGE}

The lives of objects are as complicated as those of human beings; objects change as people do. Although change is central to the conservation theory, it is also the concept that brings about the

11 Jorge Canestri, "Some Questions on Virtual Reality and Psychoanalysis", Challenges of Psychoanalysis in the 21st Century. Psychoanalysis. Health. Psychosexuality in the Era of Virtual Reality, ed. by José Guimón, Sara Zac de Filc (New York: Springer, 2001), 1-4.

12 Christina Ljungberg, "Wilderness from an Ecosemiotic Perspective", Sign System Studies, 29 (1) (2001), 169-186.

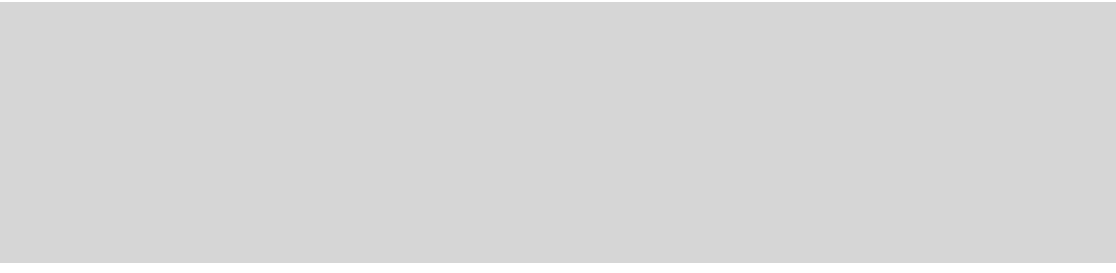

Fig. 5. Eternalist time model. Drawing by Peeter Laurits.

biggest doubts and ambiguous interpretations. The reason for this is very simple. After all, change is related to one of the basic concepts - time; and both physics and philosophy have a long way to go to find the exact definition of time. In the following discussion, I will use metaphysical theories of time as the background to treating the life course and damage of objects, and in the end, also conservation theories. ${ }^{13}$

The main metaphysical models of time are the presentist and eternalist models. According to the presentist model, there is nothing but the present and therefore, the past and the future are not real (Fig. 4). The model recognises the fact that time and changes are real and claims that everything that is real is only in the present. People live in an ever-changing present that changes into the past all the time and the future is constantly arriving but never here. Every point in time keeps moving from the future to the present and from there onwards to the past. The past does exist, of course, but only in people's memories, just as the future can only exist in our imagination. The past is over, the future has not arrived yet, so the only thing that is real is the everlasting present. The present, the current moment, is very special according to this model as this is the only thing that is real; also, a person can directly sense only this moment. The objects and events that existed in the past are no longer real in the present.

The eternalist time model (Fig. 5) is static and according to this model, all events - the ones that are taking place in the present, the ones that took place sometime in the past, and those that will take

13 An overview of time philosophy can be found in the following sources: Barry Dainton, Time and Space, Second Edition (London, New York: Routledge, 2010); Kristie Miller, "Presentism, Eternalism, and the Growing Block", A Companion to the Philosophy of Time, ed. by Heathe Dyke, Adrian Bardon (Chichester: Wiley-Blackwell, 2013), 345-364. 
place in the future - have the exact same ontological status: they exist always. The events are located on the timeline in a specific order although there are no dynamics of time. The relationships between events remain: as the discovery of America in 1492 happened before the foundation of the University of Tartu in the year 1632, then this is how it is, irrespective of the position from which we perceive the timeline. According to the eternalist theory, change means that at one unchangeable moment in time, events occur in a particular way; at another unchangeable moment of time, they are different. Objects and events are different at different moments, but there is no temporal changing between these moments. Events and objects exist on an eternal, unchangeable timeline. The fact that people use the terms "past", "present", and "future" is natural from a subjective perspective; however, objectively, there is no such thing. The model treats time similar to space: this is one dimension that can be used to describe the world; however, there is nothing special about this dimension.

Now let us see how these time models are related to the models and theories used for the preservation and conservation of objects. Firstly, let us look into how the life course of items is conceptualised. To describe the life course of objects, several models have been created but according to all of them, any object is the result of a historical process. To study these processes, a division into stages of different length usually takes place. This approach is used in history (the Stone Age, the Bronze Age, the Iron Age, ancient history, the Middle Ages, modern history, contemporary history); in the development of organisms (embryogenesis, juvenile stage, fertile period, ageing); in chronology (second, minute, hour, day, month, year, century). The history of the Earth is also divided into stages (eons, eras, periods, and epochs).

Several models of object life course have been presented. For instance, Barbara Applebaum distinguishes five stages in the life of an object: creation, original use, discard, collection, and museum acquisition in the collections of a memory institution. ${ }^{14}$ According to Cesare Brand, the famous $20^{\text {th }}$ century conservation theoretician, there are three important periods in the life of a work of art, which need to be taken into consideration during restoration: the creation of the work; the period between completion of the work and the time it reaches the consciousness of an actual perceiver; and finally, existing in the consciousness of an actual perceiver of the work..$^{15}$ Restoration can only take place in the final stage of the object. I have used the following model of the object life course. In the "biography" of an artefact, three states can be distinguished: the conceptual state, the factual state, and the current state. The life of an artefact always starts from an idea of the preparer, which is always related to the conceptual context of the preparer, i.e. a certain culture. There are no general artefacts; there are only artefacts from a specific culture, from a specific moment in time. Even the conceptual state of an artefact is itself a potential object that exists on the idea level. The following states of an artefact refer to an object that has already been realised. The factual state reflects the realised object straight after the end of the preparation process. In many cases, the factual state is merely a hypothetic construction, as the exact moment the object is ready is impossible to determine - the preparer can make changes to the object; the object might be left unfinished; someone else might finish the object, etc.

After preparation, the life of an object begins, over the course of which it is used, fixed, changed, etc. Most objects are destroyed after active use, some end up in landfill and some are recycled. As a general rule, the utilitarian value of an object diminishes due to physical, technological, and psychological obsoleting. Once an object loses its practical value, it is often thrown away or reused as raw material. A much more interesting scenario is one in which the aesthetic and symbolic value of an object increase, while its practical value decreases. For example, a utility object can be seen as a work of art, whereas both its meaning and function change.

An object's informational structure changes during its "life" and the object reaches us in its current state. The current state includes the original information (primary data), but also the information it has acquired during its use, deterioration, conservation, etc. Importantly, an object in its factual state is not identical to the object at any later point in time. It can be the same painting or the same building, 
but it is no longer a completely identical collection of physical and chemical properties, functions, meaning, and context.

Ageing is generally seen as the decrease of the information level. In fact, the informational value of an object might increase while it is ageing. Damage might add documentary value, as reflections of certain events; it may also add aesthetic value, such as patina, craquelure or the ageing of the lacquer layer on paintings. Functional properties of an object change just as the structural properties do. ${ }^{16}$

From the perspective of conservation, the changes taking place in objects are highly significant. Such changes are conditioned by the processes taking place in the objects. The processes can be grouped into physical, chemical, mechanical, and biological. These processes can be caused by several reasons, some of which are characteristic to the object itself (e.g. chemical composition, material structure, etc.), and some of which are external (e.g. temperature, humidity, biodamage, usage, vandalism, accidents, etc.). Changes can be apparent in the appearance of objects (darkening, fading, deformation, etc.), in the physical or mechanical properties of materials (change in weight, loss of flexibility, changes in transparency, etc.), or in the chemical composition (acidic paper, red rot of leather, metal corrosion, etc.). Different terms are used to describe changes: stains, soiling, mould, tears, holes, etc. Some changes are considered to be damage to objects. Which changes categorise as damage and which do not needs more specific determination. Generally, damage means any changes that are considered undesirable in a certain context. Therefore, changes are conditioned by objective processes: in the case of damage, these have been given a subjective judgment. Whether a change in an object is considered to be damage or not depends on cultural and political values. ${ }^{17}$

When speaking about object damage, a distinction must be drawn between the descriptive and normative levels. On a descriptive level, the changes that have taken place in the objects are described, and the reasons for these changes and the effect on the object are

16 This process is discussed in depth by Michael Thompson in his book: Michael Thompson, Rubbish Theory (Oxford: Oxford University Press, 1979).

17 Appelbaum, Conservation Treatment Methodology; Jonathan Ashley-Smith, Definitions of Damage (1995). See: http://cool.conservation-us.org/byauth/ashley-smith/damage.html [viewed 1.01.2017]; Kristel Van Camp, "Damage Atlas for Photographic materials", CeROArt (2010). See: http://ceroart.revues.org/1770 [viewed 11.01.2017].

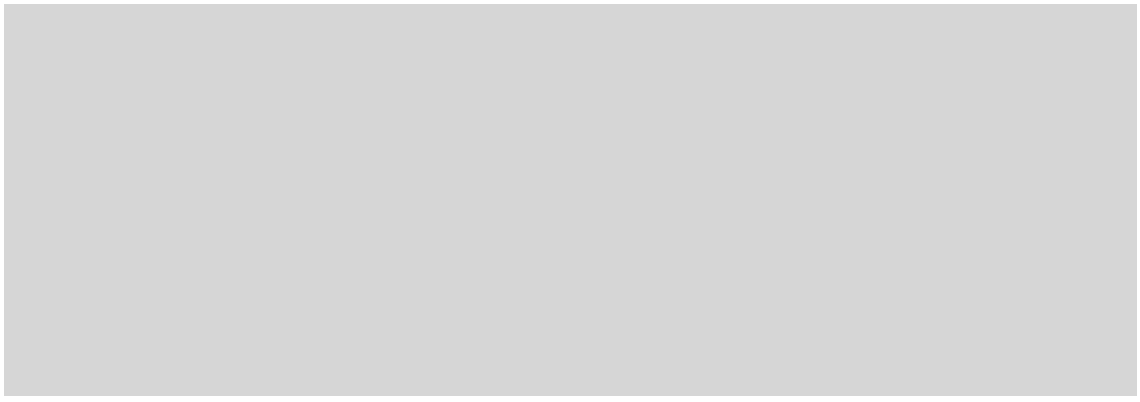

Fig. 6. Relations between changes and damages and differentiation between descriptive and normative levels. Drawing by Peeter Laurits.

clarified, if possible. On the normative level, respective normative social terminology is used to estimate whether the given changes are harmful, neutral, or useful (Fig. 6). In general, damage is understood to be a decrease in the value of an object. There are two important conclusions drawn here: firstly, only changes cause damage; and secondly, only the changes that affect the object value negatively are damage. In other words, damage is a change in the object that has a negative effect: 1) on the condition and value of an object either as a whole or partly; 2) on the value of an object as a part of some collection; 3 ) on the usage of an object or a collection that the given object belongs to.

The condition of an object describes the general physical state of the object as it relates to object materials, construction, structure, appearance, measurements, and shape. The condition and state of an object as a whole can change, but change can also affect parts of the object. For instance, the value of the artistic binding of a book can fluctuate due to changes, while the text itself might be left completely intact. The types of changes that are considered to be damage depend as well on the value attributed to the object. With objects of higher value, smaller negative changes are considered damage in comparison to objects of lower value. The definition emphasises the objects potential inclusion in collections or other related integral wholes, as this may add significant value to an object that a single object does not possess Also, the usage of objects is important, as their preservation takes place so that they can be used now as well as in the future. Describing the changes to an object on the descriptive 
level does not require the clarification of the object's value nor the reasons for these changes. On the normative level, however, it is essential to ascertain the object's value and assess the effect of the changes on that value. From the perspective of change, conservation is the intentional changing of an object, so that the value of the object will either stop decreasing or increase.

Now let us take a closer look at the object life course model in light of the metaphysical time models discussed above. From the presentist perspective, an object is actually existing and therefore important at the present moment. In the past, the object had many different states, regarding most of which we have no exact information; in the future, the object will also potentially have many different states. However, it is one and the same object over and over again, only at different moments of its history. The condition of each object is integral and authentic, clearly distinguishable from all other states of the object existing at all other moments in time, yet still identical to them as it is one and the same object! This treatment is clearly problematic for determining the object's identity and authenticity since an object is and is not simultaneously identical to its states at all other moments of time.

When looking at the object life course from the eternalist position, several interesting facts emerge. In the eternalist model, the object as a whole does not exist at a certain given moment, but in the time continuum as a whole, as it is being created until the moment of its destruction. Such an object can be imagined as a four-dimensional (three spatial dimensions and one temporal dimension) cylinder, each cut of which is the state of an object at specific moment in time and space (Fig. 5). All the states are equally real: the present state is in no way more special than a previous or a future state. The eternalist position emphasises the importance of the object as a whole, starting from the idea of its creation and ending with not even the destruction of the object, but with the disappearance of its last effects on the world. The eternalist treatment of time allows for the seeing of objects as wholes, taking into account what has happened to them before as well as the impact of current decisions and actions on the future states of an object (from our perspective) Therefore, our ethical responsibility to objects increases. Everything we do to objects remains forever and affects the objects, ourselves, the environment, and humankind on the whole.
What could the described metaphysical time models have in common with conservation theories? Upon closer inspection, it appears they have a lot in common, as both of them can be related to two almost archetypal approaches to heritage preservation: conservation and restoration. These antagonistic approaches are nowadays first and foremost connected to the names of Eugène Viollet-le-Duc and John Ruskin; however, in reality these ideas generate from a much later period and were connected to these men in hindsight. A public debate took place in the first half of the $19^{\text {th }}$ century regarding the restoration or conservation (non-restoration) of medieval buildings. ${ }^{18}$

Eugène Viollet-le-Duc (1814-1879) is known for his interpretative approach to restoration, which the critics have called destructive. In his book Dictionnaire raissone de l'Architecture francaise du XI au $X V$ siècle ${ }^{19}$ he defines restoration as follows: "The term restoration and the thing itself are both modern. To restore a building is not to preserve it, to repair, or rebuild it; it is to reinstate it in a condition of completeness which could never have existed at any given time." ${ }^{20}$

By stating the modernity of restoration, Viollet-le-Duc refers to the fact that it did not exist as such before the $19^{\text {th }}$ century. $\mathrm{He}$ underlines how special his contemporary time was as compared to previous human history: "It has undertaken to analyse the past, to compare and classify its phenomena, and to construct its veritable history, by following step by step the march, the progress, the successive phases of humanity." ${ }^{21}$ He stresses the importance of an analytical study of each building; both from the material and nonmaterial perspective. Since only a few buildings were built within a finite period of time, especially during medieval times, they had many different alternations and additions. Moreover, buildings

18 See, e.g. Nicolaus Pevsner, Ruskin and Viollet-le-Duc: Englishness and Frenchness in the Appreciation of Gothic Architecture (London: Thames and Hudson, 1969).

19 Eugène Viollet-le-Duc, Dictionnaire raisonné de l'architecture française du XI au XVIe siècle (Paris: A. Morel, 1854-1868). He speaks of restoration in $8^{\text {th }}$ volume. See: https://fr.wikisource org/wiki/Dictionnaire_raisonn\%C3\%A9_de_1\%E2\%80\%99architecture_fran\%C3\%A7aise_du Xle_au_XVle_si\%C3\%A8cle [viewed 11.01.2017]. English translation: Eugene Viollet-le-Duc, On Restoration (London: Sampson Low, Marston Low, and Searle, 1875). See: https://ia902708. us.archive.org $/ 8 /$ items $/$ onrestorationby 00 wethgoog/onrestorationby 00 wethgoog.pdf [viewed 1.2017

20 Viollet-le-Duc, On Restoration, 9

21 Ibidem, 13 
were complemented and changed even after they were finished. Therefore, stylistic restoration of buildings implied a critical study of buildings: "It is therefore essential, previous to every work of repair, to ascertain exactly the age and character of each part, - to form a kind of specification based on trustworthy records, either by written description or by graphical representation." ${ }^{22}$ Also, buildings were of different styles in different regions. Therefore, the architect had to be familiar with regional variations of the different styles and schools. Based on the study of a building, the architect had to decide how to restore the building. It is the present that matters when decisions regarding a monument are made - in which style it was built, and what the perfect embodiment of that style on the building would be. The most perfect state of an object is its original state. Wear and damage deform and distort the object; the duty of the conserver is to release the object from the desolation of time. He developed his approach as far as claiming that the original state of the object was not when it was completed, but rather when it was ready as an idea. For Viollet-le-Duc, the most important thing was the conceptual shape of an object. The aim of restoration was to reconstruct the "ideal original state" of a building, the way in which the object would have been planned and constructed under ideal circumstances at a specific moment in time. According to this model, the history of a building can be comprehended by reconstructing a series of objects that correspond to the consecutive developmental stages of the building. ${ }^{23}$ The authenticity of a building can only be judged at the present moment. ${ }^{24}$ However, he also found it important to take into account the specific characteristics and changes made in later use. An object that inevitably only exists in the present was restored so that it would correspond to a specific moment in time. This approach corresponds to a variation of the presentist time model called the "growing block" model. According to this, the constantly growing past, and the present moment as the constantly growing edge, are real. The model includes the past and the present; however,

22 Viollet-le-Duc, On Restoration, 36.

23 Thordis Arrhenius, The Fragile Monument- On Conservation and Modernity (London: Artifice Books, 2012), 63-64

24 Aaron Vinegar, "Viollet-le-Duc and Restoration on the Future Anterior", Future Anterior, 3 (2) (2006), 55-65.

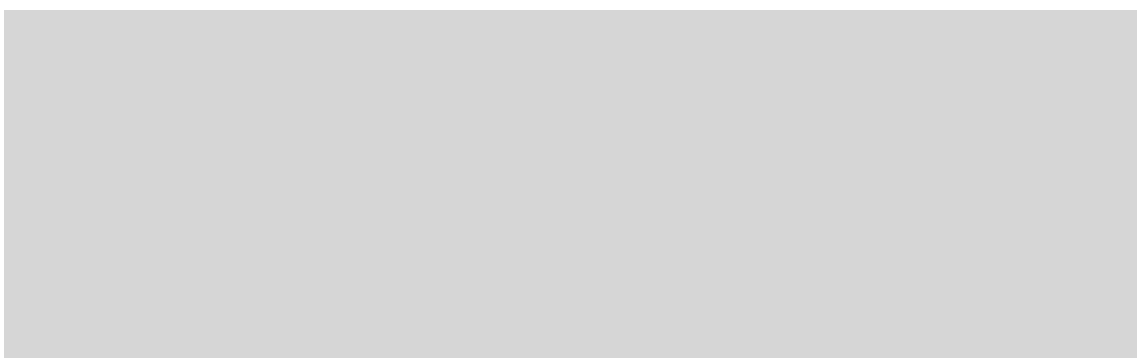

Fig. 6. Relations between changes and damages and differentiation between descriptive and normative levels. Drawing by Peeter Laurits.

the future is not included. The block is constantly growing from the past towards the future (Fig. 7).

In the middle of the $19^{\text {th }}$ century, there was a growing criticism of restoration that often led to arbitrary updates, and reconstructions that ignored historic reality. One of the leading figures of this perspective was John Ruskin (1819-1900), who did not create any conservation theories as such, but many of his viewpoints form the foundation of contemporary conservation philosophy. In his work The Seven Lamps of Architecture, he thoroughly discussed the features and values of architecture. He protected the authenticity of historic architecture in every way, stressing the value and beauty of old buildings: "For, indeed, the greatest glory of a building is not in its stones, nor in its gold. Its glory is in its Age, and in that deep sense of voicefulness, of stern watching, of mysterious sympathy, nay, even of approval or condemnation, which we feel in walls that have long been washed by the passing waves of humanity." 25

In his uttermost love for everything old, Ruskin went so far as to claim that nothing new should disturb old buildings. Old damaged buildings should not be reconstructed or restored; everything should be left the way it has reached us: "We have no right whatever to touch them. They are not ours. They belong partly to those who built them, and partly to all the generations of mankind who are to follow us." 26

25 John Ruskin, The Seven Lamps of Architecture (London: The Waverley Book Company, n.d.), 195. See: https://ia802307.us.archive.org/27/items/1920sevenlampsof00ruskuoft/1920se venlampsof00ruskuoft.pdf [viewed 11.01.2017]

26 Ibidem, 206. 
Naturally, he found restoration as an activity to be completely wrong: "Neither by the public, nor by those who have the care of public monuments, is the true meaning of the word restoration understood. It means the most total destruction which a building can suffer: a destruction out of which no remnants can be gathered: a destruction accompanied with false description of the thing destroyed." ${ }^{27}$

For Ruskin, the traces of history on an object are the greatest value of the object. The authenticity of a building does not lie in its historic form but in the traces that time has left on the building. These form part of the object and without them the object would be something completely different, thereby losing an important part of its actual nature. As the present moment was in no way significant in the history of the building, rather the other way around, it could be said that Ruskin's view on objects and their restoration is based on the eternalist time model. A building is important in its historic wholeness, starting from its creation and reaching into the faraway future. An eternalist attitude can also be found in Ruskin's view on geology, the science that sees the history of the Earth as certain periods following each other. He writes: "If only the Geologists would let me alone, I could do very well, but those dreadful Hammers! I hear the clink of them at the end of every cadence of the Bible verses." 28

For Ruskin, the term history was "the recognition of the past" rather than history in its classic meaning. ${ }^{29} \mathrm{He}$ understood history as a "strange land": past was always something that a person could not understand. ${ }^{30}$

\section{CONCLUSIONS}

Human activity in the world is always related to time and space, both providing us with opportunities and setting significant restrictions. Heritage and its preservation are no exception. Preservation means the

27 Ruskin, The Seven Lamps of Architecture, 203.

28 George P. Landow, The Aesthetic and Critical Theories of John Ruskin. See: http://www. victorianweb.org/authors/ruskin/atheories/4.2.html [viewed 11.01.2017]

29 Thordis Arrhenius, The Fragile Monument - On Conservation and Modernity (London Artifice Books, 2012), 84.

30 Richard L. Syein, "Unstable Foundations: Ruskin and the Costs of Modernity", Ruskin and Modernism, ed. by Giovanni Cianci and Peter Nicholls (Basingstoke, New York: Palgrave, 2001), $1-16$ observation of changes and, if needed, also directing such changes. It is not an attempt to "freeze" objects and phenomena in time by keeping them the same through history. Making observations and attributing meanings to something are complicated activities that require different approaches and methods. The idea of directing changes means that there is no attempt to achieve a certain outcome instead, it is a constant process that is monitored and managed. The environment is constantly changing. The result of changes that have taken place in the past is the present environment, and the changes taking place today shape the future environment in turn.

When considering previous changes to be part of an object's history, it follows that the changes taking place right now are a part of that history as well. However, people have the ability to decelerate certain changes and accelerate others, depending on set goals. The decisions made in the preservation process of heritage need to be guided by values inherent to heritage. Preservation should be such that the values and meanings characteristic of heritage remain. At the same time, it should not be left unnoticed that when making preservationrelated decisions, certain values need to be preferred over others.

Preservation is a part of the heritage management process; the way this process is carried out is also important. The main problem of contemporary preservation has clearly shifted from the question of "how" to the questions of "what" and "why". When preserving objects, places and phenomena, it is important to clearly state the values and reasons upon which the decision to preserve something has been made. Discussing heritage by using the term "technology" stresses the most important facet of the heritage process: the fact that it creates values and meanings in a culture. By creating and managing heritage, we inevitably deal with the most important processes in society.

The central problem of conservation and restoration is the question of the authenticity of objects. By applying the metaphysical time models used in the philosophy of time, I showed the possibility of determining authenticity in a different way. The essential difference between the conservation theories discussed here lies in their attitudes toward time, and the related problems of object authenticity and identity. In the framework of the presentist model, it is not possible to solve the main contradiction connected to restoration. Stylistic restoration ruined the authenticity of buildings as historic 
documents; however without restoration, the objects would have been destroyed and thereby also lost their historic value. However, it is possible to find a solution to this dilemma based on the eternalist time model, which helps connect heritage to contemporary time, and avoid its physical, legal, and mental separation from everyday life of society. The fact that considering objects as part of heritage could damage them instead of preserving them should also not be overlooked. The authenticity of an object is not related to any ideal state in its history but to a conceptual, factual and actual state in its wholeness.

Kurmo Konsa: Time and space of heritage preservation: Conservation theoretical perspective

Keywords: Culture; Heritage; Conservation; Restoration; Metaphysical Time Models; Viollet-Le-Duc; John Ruskin

\section{SUMMARY}

In this article, I discuss the categories of time and space in light of heritage conservation. I demonstrate that heritage creation is the simultaneous creation of human time and space and that the critical treatment of heritage requires a more specific analysis of these terms. First, I look at how the creation of human space occurs through objects, and how the objects of the physical environment become things, i.e. parts of our living world. The world can only be understood through change. This is a fundamental finding that forms the basis for both elementary senses and complicated philosophies. In order to explain the change in heritage-related space, I am using the terms artificialisation and heritage technology. Artificialisation means the anthropogenic transformation of the environment, which takes place mainly with the help of technological systems. Therefore, the environment encompasses physical, biological and genetic environments, as well as the human culture with its past. In this environment, it is impossible to distinguish between the human and non-human, since they make up a single hybrid whole. Artificialisation is by no means a determined course in history; it is a human means of description, a metaphor that helps to explain the processes ongoing in nature and human society. According to this approach, the heritage process is one technique in the artificialisation of the environment.

Although change is central to conservation theory, it is also a concept that causes the greatest doubts and ambiguous interpretations. The reason for this is very simple: change is related to time, which is a foundational concept. In this article, I use metaphysical time models to analyse the life course of things and their damage. Finally, I also refer to the conservation theories of Eugène Viollet-le-Duc and John Ruskin. The essential difference between the conservation theories that are discussed here lies in their attitudes toward time, and the related problems of object authenticity and identity. In the framework of the presentist model, it is not possible to solve the main contradiction connected to restoration. Stylistic restoration ruins the authenticity of buildings as historical documents; however without restoration, the objects would be destroyed and thereby lose their historical value. However, a solution to this dilemma can be found based on the eternalist time model, which helps connect heritage to contemporary time, and avoid its physical, legal, and mental separation from the everyday life of society. The fact that including objects as a part of heritage may damage them instead of preserving them should not be overlooked. The authenticity of an object is not related to any ideal state in its history but to a conceptual, factual and actual state in its wholeness.

\section{CV}

Kurmo Konsa (b. 1965) is an Associate Professor at the Department of Archival Studies at the University of Tartu, and Professor of Conservation at Tartu Art College. He has an MSc in microbiology from the University of Tartu, and an MA in Book Science from Tallinn University. Kurmo Konsa holds a PhD in Informational Science from Tallinn University. His PhD thesis focuses on the preservation of written heritage and conservation surveys issues. In the past he has worked at the University of Tartu Library as a paper conservator and at the Estonian Postal Museum as Conservator and Curator of Collections. 
